\title{
PRECARIZAÇÃO DO TRABALHO DOCENTE E SEUS EFEITOS SOBRE AS PRÁTICAS CURRICULARES
}

\author{
Maria das Mercês Ferreira Sampaio* \\ Alda Junqueira Marin ${ }^{* *}$
}

\begin{abstract}
RESUMO: Este artigo trata do comprometimento da função cultural da escola básica brasileira, como fruto de determinadas condiçôes econômicas e sociais que incidem sobre seu trabalho, tornando-o frágil e insuficiente. Também expõe e analisa dados sobre a precária situação do trabalho docente e suas conseqüências sobre as práticas curriculares que têm origem na legislação educacional vigente no país.
\end{abstract}

Palavras-chave: Precarização. Docência. Currículo.

\section{TEACHER'S WORK PRECARIZATION AND CURRICULUM PRACTICES}

ABSTRACT: This paper show how the cultural function of the Brazilian basic school is jeopardized by the economic and social conditions that make its work it fragile and insufficient. It presents and analyses some results on the precariousness of the teacher's work situation and its consequences on the curriculum practices, which have their origin in the educational laws existing in Brazil.

Key words: Precarization. Teaching. Curriculum.

* Doutora em Educação, professora e pesquisadora do Programa de Estudos Pós-Graduados em Educação: História, Política, Sociedade, da Pontifícia Universidade Católica de São Paulo (PUC-SP).E-mail:mfs@dialdata.com.br

** Livre-docente em Educação, professora e pesquisadora do Programa de Estudos Pós-Graduados em Educação: História, Política, Sociedade, da Pontifícia Universidade Católica de São Paulo (PUC-SP). E-mail: aldamarin@pucsp.br.

Educ. Soc., Campinas, vol. 25, n. 89, p. 1203-1225, Set./Dez. 2004

Disponível em <http://www.cedes.unicamp.br> 
E

ste artigo pretende apresentar uma discussão sobre a precarização do trabalho escolar expressa nas práticas curriculares. Portanto, compóe-se de duas partes: a primeira apresenta dados relevantes para situar a atuação da escola nos dias atuais, e a segunda traz um recorte de algumas práticas curriculares desenvolvidas no interior da escola, discutindo-as na relação com os dados inicialmente apontados.

Consideramos que problemas ligados à precarização do trabalho escolar não são recentes no país, mas constantes e crescentes, e cercam as condições de formação e de trabalho dos professores, as condições materiais de sustentação do atendimento escolar e da organização do ensino, a definição de rumos e de abrangência do ensino secundário e outras dimensões da escolarização, processo esse sempre precário, na dependência das priorizações em torno das políticas públicas. Notadamente a partir dos anos 70 do século XX, acentua-se no país o agravamento das condições econômicas e a deterioração do sistema público de ensino, a par de sua expressiva expansão, repercutindo com efeitos desastrosos no funcionamento das escolas, especialmente nos grandes centros urbanos (Paiva et al., 1998).

Nas décadas seguintes, 1980 e 1990, as interferências dos organismos internacionais de financiamento, já presentes e decisivas, tornamse mais expressivas, incidindo sobre os rumos da escolarização e sobre a formação de seus profissionais. No concerto de projetos sociais e acordos necessários aos arranjos da globalização (Coraggio, 2000), as políticas educacionais geradas nesse período se explicitam, inclusive, em redirecionamentos curriculares.

Já se produziram diversas análises das recentes políticas educacionais e reformas de ensino, que discutem as implicações da globalização econômica e da hegemonia política do neoliberalismo sobre a educação brasileira. Recentemente divulgado, o estudo de Dale (2004), por exemplo, permite compreender as relaçōes fundamentais entre a necessidade de manter e fortalecer o sistema capitalista, as mudanças na economia mundial, as alterações nas políticas educacionais e a atuação decisiva dos organismos internacionais, que definem modelos curriculares atrelando financiamentos à adesão a suas orientações e abordagens em educação. Mudanças curriculares determinadas nesse quadro de relaçóes de poder econômico e político só podem ser compreendidas no contexto de compromissos que geram projetos e políticas sociais e culturais. 
O atual currículo prescrito, portanto, explica-se no conjunto das medidas consideradas necessárias ao alinhamento do país às prioridades acordadas no âmbito internacional. Sua importância não pode ser superestimada, mas está claramente afirmada na forma como se impóem os parâmetros curriculares, articuladamente às avaliaçôes externas, que classificam as escolas e as obrigam a redirecionar seu trabalho pedagógico.

Compreender as práticas curriculares nesta perspectiva, atravessadas pelas exigências da nova ordem econômica e política, torna-se necessário, ainda que difícil. Exige conhecer e analisar o currículo prescrito e, sobretudo, investigar o currículo real, aquele que se desdobra em práticas no interior da escola, cuja determinação não se origina apenas das prescrições oficiais, mas de muitos fatores que interferem no desenvolvimento do trabalho escolar. Seus determinantes expressam tanto as marcas das políticas quanto as condições e os problemas sociais e econômicos que atingem a vida de seus usuários. Daí que o exercício de pensar algumas práticas necessita situá-las na relação com alguns outros elementos mais amplos, como os que cercam o trabalho dos professores e são apontados a seguir.

\section{Necessidade de escolaridade e de professores}

Uma busca de informações sintetizadas sobre o crescimento das necessidades, e o atendimento, de escolaridade para a educação fundamental e média nas últimas décadas do século XX forneceu um quadro em que se verifica o enorme salto dado nesse particular:

- cerca de 3,3 milhōes em 1945, 5,6 em 1955, 11,6 milhóes em 1965, 19,5 milhões em 1975, 24,8 milhões em 1984 e 31,2 milhōes em 1994 no ensino fundamental;

- cerca de 1,9 milhão em 1975, 3,0 milhōes em 1984 e 5,1 milhões em 1994, segundo dados expostos por Paiva et al. (1998).

Tal realidade não seria viável sem a conseqüente busca, na sociedade, de quadros de pessoal que preenchessem as vagas para a função docente de modo que concretizassem a tarefa educativa.

Como consequiência, o número de funçōes docentes no período passou de 248 mil, em 1960, para 1.377.665, em 1994, segundo as 
informaçōes obtidas por Paiva et al. (1998) no MEC. Dados mais detalhados da fase inicial aqui focalizada também podem ser encontrados em Fernandes (1966) e Werebe (1968).

Esta é uma informação para o Brasil que se relaciona com um quadro mais amplo: na América Latina e no Caribe, entre 1990 e 1995, o aumento de professores para a educação primária foi de $12,2 \%$ e para a educação secundária foi pouca coisa menor, ou seja, 11,6\% (Siniscalco, 2003).

O crescimento brutal e constante, assinalado acima, só foi possível em razão de alguns fatores. O primeiro deles foi o recurso ao amplo contingente da população considerado economicamente ativo, porém fora do mercado de trabalho. Nessa circunstância, as mulheres desde o século XIX consideradas as mais adequadas para o exercício do magistério (Tanuri, 2000) - foram gradativamente incorporadas aos quadros empregadores do magistério, tornando-o um foco dos estudos de gênero nos anos recentes. A feminilização do magistério, portanto, está, por um ângulo, ligada a tal circunstância, não só no Brasil como na América Latina e no Caribe:

- em 1990 havia 1,5 milhão de homens e 3,6 milhões de mulheres em exercício no magistério; em 1997 esse total evoluiu para 1,8 milhão de homens e 4,2 milhões de mulheres, segundo os dados apresentados por Siniscalco (2003). Verifica-se o crescimento de ambos os segmentos, porém o crescimento do público feminino é proporcionalmente maior que o do masculino.

Tal crescimento dos quadros do magistério leva a outras informações. Uma delas é a de se considerar a idade, pois é principalmente o segmento mais jovem da população o convocado para tais postos. Os dados relativos ao perfil etário da profissão docente permitem verificar que o Brasil é o segundo país mais jovem em matéria de docentes da educação primária, e o quarto no âmbito das séries finais do ensino secundário (Siniscalco, 2003): (Ver tabela 1).

Uma terceira faceta relacionada a tais necessidades refere-se à natureza da qualificação dos professores. $\mathrm{O}$ crescimento alto e rápido de tal oferta de escolaridade e o recrutamento de docentes para efetivar tal escolarização da população certamente não contavam com quadros de reserva qualificada para a função em todas as décadas. Na passagem da década de 1950 para a de 1960 havia, em São Paulo, um contingente de 
professores primários formados; em 1955 havia 25 mil professores primários sem emprego (Pessanha, 2001, apud Vieira, 1987), que certamente ingressaram no magistério nas décadas seguintes. Porém, era um contingente ainda insuficiente, e se referia apenas à realidade de um estado. Os órgãos governamentais vêm tomando decisões para enfrentar tal precariedade ao longo das décadas, de modo que possam suprir, sobretudo, as redes públicas de ensino: contratação de pessoal sem habilitação por meio de medidas variadas de autorização para lecionar e medidas de certificação de pessoal por meio de certos tipos de exames que apontem, pelo menos, o domínio dos conteúdos a serem ensinados por parte dos candidatos a docência.

\section{Tabela 1}

Freqüência de professores segundo o âmbito de atuação e a faixa etária

\begin{tabular}{|c|c|c|c|c|}
\hline \multirow{2}{*}{ Âmbito escolar } & \multicolumn{4}{|c|}{ Faixa etária } \\
\cline { 2 - 5 } & $\begin{array}{c}\text { menos } \\
\text { de 30 anos }\end{array}$ & $\begin{array}{c}\text { entre } \\
30 \text { e 39 }\end{array}$ & $\begin{array}{c}\text { entre } \\
40 \text { e 49 }\end{array}$ & $\begin{array}{c}\text { entre } \\
50 \text { e } 59\end{array}$ \\
\hline Educação primária & $35 \%$ & $36 \%$ & $22 \%$ & $5 \%$ \\
\hline $\begin{array}{l}\text { Educação secundária } \\
\text { (séries finais) }\end{array}$ & $29 \%$ & $32 \%$ & $28 \%$ & $8 \%$ \\
\hline
\end{tabular}

Fonte: Siniscalco (2003)

Essa situação, mais freqüente nas décadas de 1960 e 1970, ainda vigora no Brasil. Em estudo realizado com a participação de diversas entidades nacionais e da Organização das Nações Unidas para a Educação, a Ciência e a Cultura - UNESCO (2004), entre vários dados dispostos sobre ensino fundamental e médio, é possível verificar, em âmbito nacional, a condição de formação básica dos professores, sem dúvida representativa de nossa realidade. A Tabela 2 aponta a proporção de docentes com e sem habilitação no país, tanto no ensino fundamental como no ensino médio, com dados da pesquisa UNESCO já referida (p. 79).

Detalhando um pouco mais tais dados, sobre professores com formação superior, vamos encontrar uma escala que varia de $10 \%$ no Maranhão a 76\% em São Paulo (Brasil, 2002). 


\section{Tabela 2}

Proporção de professores, por nível de ensino de atuação, segundo a habilitação

\begin{tabular}{|l|c|c|}
\hline habilitação & ensino fundamental & ensino médio \\
\hline $\begin{array}{l}\text { ensino médio com formação } \\
\text { pedagógica (ens. normal) }\end{array}$ & 29,0 & 9,3 \\
\hline $\begin{array}{l}\text { ensino médio sem formação } \\
\text { pedagógica }\end{array}$ & 5,5 & 3,5 \\
\hline $\begin{array}{l}\text { ensino superior com formação } \\
\text { pedagógica (licenciatura) }\end{array}$ & 60,3 & 80,3 \\
\hline $\begin{array}{l}\text { ensino superior sem formação } \\
\text { pedagógica }\end{array}$ & 5,1 & 6,9 \\
\hline
\end{tabular}

Se, por uma especificação ainda maior com relação ao âmbito de atuação, tomarmos dados relativos ao Estado de São Paulo, encontraremos, por exemplo, as seguintes conclusões nos estudos de Patinha (1999) e Paiva (2002):

- professores que atuam sem habilitação, a cada ano, em disciplina diferente daquela lecionada no ano anterior;

- professores que atuam, ao mesmo tempo, em disciplinas de áreas diferentes;

- professores que não constam mais das relações da Secretaria da Educação como não habilitados, mas classificados como PEB I, ou seja, similares a professores primários; um artifício administrativo para ocultar tal situação.

Por tais especificações, oriundas de pesquisas - que podem ser supostas para outros estados -, verificamos que formação no ensino superior não significa formação específica para docência, ou seja, uma licenciatura que habilite o profissional para tal função.

Um dos aspectos a serem lembrados refere-se ao exercício da profissão e aos estudos relativos ao aprendizado dela. As pesquisas têm trazido dados reveladores: os professores em exercício manifestam-se di- 
zendo aprender com a experiência, ou seja, professores, sobretudo os iniciantes, alegam forte influência da prática para aprender a ser professor, tanto no que tange aos aspectos pedagógicos como a outros aspectos da profissão (Ferreirinho, 2004). Nos aspectos pedagógicos, a revisão bibliográfica realizada por Guarnieri (1996) informa-nos, por exemplo, que os professores não têm familiaridade com os conteúdos a serem ensinados, nem com os tipos de dificuldade dos alunos; eles têm dificuldade de transformar os conhecimentos adquiridos anteriormente em conteúdos ensináveis. Sua pesquisa aponta outros dados: uma professora, focalizada de modo mais intenso e extenso, tinha dificuldade de organizar a seqüência de ensino, não sabendo em que momento prosseguir com a matéria, e tinha dificuldade para organizar atividades escolares para os alunos, aspectos centrais da concretização do currículo que só foi aprendendo com o passar do tempo.

Outras situações podem nos fazer pensar na precarização do trabalho dos professores iniciantes. Trata-se da aprendizagem com colegas mais experientes. Em décadas anteriores, essa prática era muito comum: as professoras primárias mais experientes e bem-sucedidas em seu trabalho viam seus diários e semanários disputados pelas mais jovens ou pelas que enfrentavam dificuldades. As mais velhas eram requisitadas para auxiliar a resolver questóes difíceis enfrentadas pelas colegas mais novas ou mais inexperientes. Tais situações foram se tornando mais raras com o passar das décadas, pois há escolas - e não são poucas - que não possuem professores com anos de experiência e saberes adquiridos para transmitir aos mais novos. Além disso, a prática dos diários e semanários se perdeu, sendo substituída por outros mecanismos menos registradores das trajetórias diárias de ensino.

Outros elementos de preocupação com relação ao currículo e à precarização do trabalho dos professores, com dados apontados anteriormente, referem-se ao fato de muitos trabalharem com conteúdos diversificados ao mesmo tempo e por anos seguidos: há que se questionar o domínio de tantos conteúdos escolares - quase todos os da escola secundária - ministrados por um profissional formado em administração de empresas!, por exemplo, ou, ainda, um licenciado em educação física que lecione química ou matemática. Além disso, o contingente de não habilitados significa, também, a ausência de formação pedagógica e o enfrentamento de realidades escolares muito diferentes das que viveu como aluno e, com outra perspectiva, da realidade de professor. 


\section{Salário}

Uma das questões bem visíveis da precarização do trabalho do professor refere-se ao salário recebido pelo tempo de dedicação às suas funçóes, sobretudo quando se focaliza a imensa maioria, ou seja, os que atuam nas diversas escolas da rede pública.

Os dados apresentados por Siniscalco (2003) atestam a dureza dessa realidade em comparação com outros países, inclusive aqueles com piores condições sociais e econômicas: o Brasil está acima apenas da Indonésia e quase empata com o Peru. Todos os demais oferecem salários mais elevados na educação primária. $\mathrm{Na}$ educação secundária também é um dos sete piores do mundo.

Dados de 1997 informam-nos que o cálculo bruto da média salarial de docentes da educação básica brasileira era de $\mathrm{R} \$ 529,92$, numa escala que variava de $\mathrm{R} \$ 221,22$ (na Paraíba) a $\mathrm{R} \$ 1.364,30$ (no Distrito Federal) (Brasil, 2002). Além disso, é de se questionar a política salarial dos órgãos públicos quando se comparam as médias entre o âmbito federal ( $\mathrm{R} \$ 1.527,01)$, a dependência administrativa estadual ( $\mathrm{R}$ \$ $584,56)$ e a municipal ( $\mathrm{R} \$ 376,67)$, sem levar em conta as médias das redes privadas, às vezes consideradas melhor pagadoras, porém não generalizadas nem tão mais elevadas, o que significa, também, desconsideração pela função docente nesse âmbito (Brasil, 2002).

A situação salarial brasileira melhora um pouco com o passar dos anos de atividade docente, por meio dos incentivos dados como adicionais por tempo de serviço ou de qualificação. Assim mesmo permanecem em posição bem inferior quando comparados com os incentivos dados em outros países.

Esse é um fator que incide pesadamente sobre a precarização do trabalho dos professores, pois a pauperização profissional significa pauperização da vida pessoal nas suas relaçôes entre vida e trabalho, sobretudo no que tange ao acesso a bens culturais.

O estudo realizado pela UNESCO (2004) no país revelou que os maiores indicadores nessa área foram:

- $62 \%$ nunca freqüentam concerto de música erudita, $14 \%$ não freqüentam museus e $17 \%$ não freqüentam teatro;

- $33 \%$ assistem a fitas de vídeo uma vez por semana; $49 \%$ vão ao cinema algumas vezes por ano. 
Desagregando-se esses dados, verifica-se que os homens são mais freqüentes nos eventos focalizados na pesquisa. Como a maioria do corpo docente é formada por mulheres, pode-se inferir, sem grande esforço, como esse acesso é precário.

Se pensarmos que tais eventos ocupam o tempo livre dos professores, há que se verificar outras facetas do acesso a bens culturais, incluindo aqui as relativas ao desempenho da profissão. Os dados obtidos por essa pesquisa da UNESCO nos mostram respostas induzidas a uma lista de atividades, lembrando que parte dos entrevistados atua em escolas privadas, às vezes recebendo salários melhores, se comparados com os da rede pública:

- apenas 47,9\% lêem revistas especializadas em educação habitualmente ou sempre e $46,5 \%$ lêem às vezes;

- $44,5 \%$ dos professores fotocopiam materiais habitualmente ou sempre e $43,2 \%$ às vezes;

- $22,9 \%$ compram livros (não didáticos) habitualmente e $58,5 \%$ compram às vezes;

- quase 7\% nunca lêem jornais ou revistas;

- $40 \%$ lêem jornal diariamente, $22,6 \%$ lêem de três a quatro vezes por semana e $23,5 \%$ lêem uma ou duas vezes por semana.

É compreensível que não possam ter acesso a tais bens culturais, principalmente quando o empobrecimento profissional vem acompanhado da informação sobre a renda familiar: a grande maioria tem renda familiar entre 2 (dois) e 10 (dez) salários mínimos!

É quase evidente, por si, a relação de tais dados com as questões de currículo: o estudo, a atualização dos professores, o acompanhamento do que ocorre na esfera cultural e no mundo está fora do universo desses profissionais. O processo de realimentação quanto a informações, em geral, fica restrito à freqüência a cursos de especialização, que muitos deles apontaram, ou estar sintonizado com o mundo é uma possibilidade que ocorre por meio da televisão, quando há tempo.

Deve-se ressaltar aqui a perda da relevância dos conteúdos no desempenho de sua atividade educativa. Buscar a atualização, o estudo no campo específico de sua formação ou no que se refere a aspectos 
pedagógicos, é pouco importante, pois os dados da investigação da UNESCO indicam que:

- entre as finalidades mais importantes da educação, $72,2 \%$ dos professores afirmaram que o mais importante é formar cidadãos conscientes, assim como $60,5 \%$ indicaram que é desenvolver o espírito crítico, contra 8,9\% que apontaram ser o de proporcionar conhecimentos básicos!

- 21,4\% afirmaram que transmitir conhecimentos básicos é um dos objetivos menos importantes!

Induzidos a responder sobre duas alternativas quanto ao papel do professor na atividade educativa, $17,3 \%$ desses profissionais manifestaramse dizendo que o professor é um transmissor de cultura e conhecimento, ao passo que $79,2 \%$ escolheram a alternativa de que o professor é um facilitador da aprendizagem do alunado. Apenas 3,4\% não se identificaram com nenhuma das alternativas. Indicadores de precariedade da efetivação de um trabalho educativo escolar podem ser percebidos à medi$\mathrm{da}$ que relacionamos tais respostas com as anteriores, sobre os objetivos da educação a serem perseguidos: de que são feitas as situações facilitadoras de aprendizagem para formar cidadãos conscientes e sobre o que exercer o espírito crítico?

Outros estudos como o de Lourencetti (2004), por exemplo, mostram que os docentes têm clareza desse esvaziamento de conteúdos, sobretudo na escola pública.

\section{Condições de trabalho}

A análise da precarização do trabalho dos professores com relação às condiçóes de trabalho precisa ocorrer em diferentes facetas que o caracterizam. Dentre essas facetas destacamos: carga horária de trabalho e de ensino, tamanho das turmas e razão entre professor/alunos, rotatividade/itinerância dos professores pelas escolas e as questóes sobre carreira no magistério.

\section{Carga horária de trabalho/de ensino}

Os dados divulgados por Siniscalco (2003) abarcam as horas de trabalho em geral e as horas utilizadas para o ensino, com os alunos. 
A carga horária de trabalho dos professores brasileiros não consta do levantamento apresentado pela autora em razão de os dados não terem sido enviados à Organização Internacional do Trabalho (ОIT), uma das instituições que colaboraram para o estudo. Entretanto, outros estudos mostram que, sobretudo na última década, diversas instituições públicas e privadas implantaram este tipo de apoio: horas para o desenvolvimento das atividades de preparo de aulas, de correção de trabalhos de alunos, apoio aos alunos nas atividades extracurriculares e de formação em serviço para os próprios professores. Essas atividades ligadas ao currículo das escolas, feitas fora da sala de aula e da presença de alunos, recebem nomes e organizações diversas nas redes de ensino: Horário de Trabalho Pedagógico Coletivo (HTPC), horas-atividade individuais ou coletivas, realizadas nas escolas ou em ambientes de escolha dos professores.

Nos demais países, essa carga horária de trabalho não-instrucional tem sido estimada entre $10 \%$ e $50 \%$ da semana de trabalho. $\mathrm{Na}$ Espanha, por exemplo, para 890 horas anuais de ensino os professores têm um acréscimo de 494 horas para o desempenho de outras atividades, o que significa um acréscimo de cerca de 9 horas semanais, em média, na educação primária.

No que tange às horas relacionadas ao ensino propriamente dito, o Brasil tem, por lei (9.394/96), a definição de 200 dias letivos por ano, ou seja, 4 horas em média por dia, num total de 800 horas/ano para toda a educação fundamental e média. Essa não é a média dos países europeus, cuja carga tende a decrescer nas séries finais do ensino fundamental. Especificações maiores podem ser obtidas com informaçōes de 2001: a média brasileira em horas para o ensino fundamental regular era de 4,3 numa escala que variava de 3,9 no Ceará a 4,9 no Distrito Federal; no ensino médio a média era de 4,3 com escala variando de 3,9 em Santa Catarina a 4,9 no Distrito Federal (Brasil, 2002).

Algumas questões relacionadas à precarização do trabalho docente na sua relação com o trabalho pedagógico dizem respeito ao uso efetivo dessas horas de trabalho fora da sala de aula. Uma delas é a que se relaciona ao HTPC ou horas-atividade de uso coletivo nas escolas. Elas somente foram acrescidas à carga horária de trabalho dos professores a partir da reivindicação deles próprios. Estudos relacionados a tais atividades (Lourencetti, 2004), porém, vêm indicando que: 
- os HTPCs raramente são utilizados para rever, debater ou obter auxílios coletivos relativos a questões de efetivação do currículo, e sim como tempo dedicado a questóes administrativas;

- as horas-atividade de grande parte dos professores são utilizadas individualmente e fora do ambiente escolar, portanto, sem a garantia de que de fato constituam tempo de estudo para atualização ou busca de soluções aos problemas enfrentados na prática de sala de aula;

- nas séries de $5^{a}$ a $8^{a}$ não é obrigatória a atribuição de tal carga de trabalho, fato que estabelece disparidade de condição de trabalho entre os professores de uma mesma escola.

Evidentemente, tal situação tem a ver com outras condiçôes de trabalho, como as relacionadas a salário, por exemplo, tendo em vista o número de escolas em que trabalham e o número de horas/aula que assumem, sobretudo para os professores que atuam nas séries finais do fundamental e no ensino médio, que às vezes tresdobram a jornada em redes diferentes de ensino. Os professores das séries iniciais, em alguns locais, ainda dobram a jornada assumindo carga horária em escolas de redes públicas diferentes - estadual e municipal - ou em escolas públicas e privadas.

\section{Tamanho das turmas}

Outra faceta ligada diretamente às condições de trabalho diz respeito ao tamanho das turmas com as quais os professores devem trabalhar.

O levantamento realizado e divulgado por Siniscalco (2003) indica a relevância desse dado para a análise das condições de trabalho e das condições e/ou dos resultados de aprendizagem do alunado. Com base em dados verificados nos indicadores divulgados pela Organização para Cooperação e Desenvolvimento Econômico (OCDE), a autora comenta sobre a impossibilidade de se obter dados conclusivos sobre a condição numérica da turma e os resultados de aprendizagem. Há pistas de que as classes menos numerosas sejam as que conseguem melhores resultados, sobretudo na educação pré-primária e primária, porém tais dados devem ser examinados levando-se em conta outros elementos, acerca de seleção e organização do currículo, procedimentos de ensino e atendimento aos alunos. 
No Brasil verifica-se uma queixa constante dos professores quanto a esse aspecto. Em muitos locais em que foi feita a reorganização das escolas da rede pública houve situações de algumas formarem turmas excessivamente numerosas, contando com a evasão de alunos para atingir uma composição numérica mais equilibrada.

Os dados de 2001 divulgados pelo Instituto Nacional de Estudos e Pesquisas Educacionais (INEP), ligado ao MEC (Brasil, 2002), revelam que o número médio de alunos por turma era de 28,3 , numa escala que variava de 22,2 em Roraima a 32,9 em Alagoas, no ensino fundamental regular, e 37,6 no Brasil variando de 30,9 em Roraima a 43,0 em Sergipe.

\section{Razão professor/alunos}

A faceta do tamanho das turmas relaciona-se diretamente com questões envolvendo a razão entre professor e alunos.

Razões entre professor e alunos, segundo Siniscalco (2003), são mais facilmente obtidas, mas acabam mostrando que o resultado é pior que o do tamanho das turmas, por razóes diversas decorrentes da estruturação das redes escolares.

No período entre 1990 e 1997, na América Latina e no Caribe, a razão aqui focalizada, no ensino primário, foi de:

1990 - 25,1 alunos;

1991-1997 - 24,5 alunos.

No Brasil, a razão entre professores e alunos no ano de 1999 foi de:

- educação primária (ensino fundamental) - 28,9;

- educação secundária - séries iniciais (ensino fundamental) - 33,7;

- educação secundária - séries finais (ensino médio) - 38,4.

Estes números estão bem acima, por exemplo, da média obtida pelos países da OCDE, em que a razão é de 17 para a educação primária, 15 para as séries iniciais do secundário e 14 para as séries finais do secundário.

Essas taxas altas ou baixas se relacionam com fenômenos de evasão escolar e taxas de matrícula de alunos. Além disso, alguns aspectos 
apontados dizem respeito à elevação das taxas quando os professores se dedicam a turnos duplos ou triplos na mesma instituição. Essa é uma situação muito comum na organização das escolas públicas e privadas brasileiras. Os professores são, comumente, responsáveis por várias turmas em dois turnos de funcionamento das escolas: manhã/tarde, manhã/ noite ou tarde/noite, sobretudo quando se trata das séries finais do ensino fundamental e das séries do ensino médio. Esse é um dado ainda mais relevante quando se verificam quais disciplinas do currículo se focalizam: em história, geografia e educação artística, por exemplo, é menor o número de aulas (duas semanais) que em matemática ou português (quatro ou cinco semanais). Como resultante, o professor destes componentes curriculares assume menos períodos que o professor dos componentes anteriormente referidos. Portanto, são computados mais alunos para um mesmo professor, que atua em maior número de turmas. Esse é um elemento de forte incidência sobre a precarização do trabalho do professor, o qual, para preencher uma carga horária de trabalho que lhe forneça subsistência, precisa trabalhar com um volume de cerca de 600 jovens!

\section{Rotatividade/itinerância}

Ao lado dessas facetas, encontramos, ainda, dois fenômenos, na educação brasileira, cujas características já foram tocadas rapidamente. Trata-se da rotatividade de professores nas escolas, de um ano para outro ou, às vezes, num mesmo ano, e da itinerância deles por várias escolas, ao mesmo tempo, ao longo do ano, como vem sendo analisado desde o início da década de 1990 (Dias da Silva \& Chakur, 1990).

Levando-se em conta as condiçôes mais amplas em que se realiza o atendimento escolar no país, sua inserção nas políticas decididas externamente, pelos organismos internacionais, e a relação entre os vários indicadores apresentados, compreende-se que a função cultural da escola vem sofrendo prejuízos que se abatem sobre o trabalho docente e, sobretudo, sobre a formação dos alunos.

A precarização do trabalho escolar faz-se presente no currículo, cuja problemática diz respeito não só aos conteúdos básicos da escolarização. Nas expressões do currículo escolar explicita-se como se pensa e se avalia a sociedade, quais modelos humanos são apontados ou desvalorizados, quais crenças são respeitadas, como se vivem as diferenças, o que ainda vale a pena na escola. Também se identificam condiçôes de trabalho e de 
reflexão da escola, aberturas e amarras do processo de conhecimento, os jogos de poder e convencimento do texto curricular, os focos de desencanto e de esperança de professores e alunos com relação à escola.

Expressam-se, também, as determinaçōes, imposiçōes ou simples orientações do sistema de ensino sobre questôes que organizam o cotidiano escolar. Ainda que as formas de controle de sua realização sejam decisivas, diferentes graus de legitimidade, sintonia e precisão dessas diretrizes resultam em diferentes formas de adesão e de operacionalização das medidas preconizadas. Também interfere na implementação o sentido ou a direção das mudanças propostas, isto é, o modo como alteram o currículo e o que anunciam de ganhos, de fato, para o professor: se entram facilitando e valorizando seu trabalho, ou com sobrecarga e desordem nesse processo. Isso tem muito peso, ainda que as propostas sejam compreendidas como legítimas nas respostas a problemas, claras em sua intenção e em seus modos de implementação, e sintonizadas com as condições e formas de trabalho da escola e com tentativas já instaladas na prática.

Nesse cruzamento de fatores é que as intervenções centradas no currículo ou na organização do processo de escolarização com efeitos que atingem o currículo podem ser compreendidas e discutidas, seguindo-se o fio de seu eixo principal e os seus desdobramentos sobre as práticas. Freqüentemente, o eixo central de propostas com foco no currículo sustenta-se na organização do ensino, desdobrando-se em reflexos sobre a aprendizagem dos alunos, e as propostas centradas na organização mais ampla têm como foco e eixo a aprendizagem e os resultados, por parte dos alunos, tendo reflexos no processo de ensino, ou seja, na organização da prática docente. Essas relações e suas conseqüências serão discutidas a seguir, comentando-se algumas propostas que se originam da legislação de ensino vigente.

Detendo a atenção sobre as orientações que recaem sobre o currículo do ensino fundamental, constata-se que algumas delas, em novo enfoque, induzem a uma organização do ensino por projetos que expressem, ao mesmo tempo, articulaçôes entre disciplinas e relações com questôes sociais, ou de "vida cidadâ", nos termos oficiais, conforme orientam as Diretrizes Curriculares Nacionais (DCN). ${ }^{1}$ A proposta pedagógica recai, portanto, sobre conteúdos e formas de ensino, aspectos entranhados, que não se separam, mas podem assumir proporçôes diferentes em diversos arranjos do mesmo discurso. A alteração curricular, dessa forma, estende-se ou tem conseqüências sobre a aprendizagem dos alunos. Por sua vez, a orga- 
nização do ensino em ciclos, com foco na reordenação do processo de aprendizagem dos alunos - que terão de permanecer por mais tempo na escola -, tem conseqüências sobre a prática docente e também recai sobre o conteúdo e a forma em que se expressa o currículo.

São complexas as mudanças pretendidas, objetivando articular e mudar o foco dos conteúdos e também organizar o processo pedagógico de modo que possibilitem aprendizagem contínua e avanços diferenciados aos alunos. Como parece evidente, são alterações marcadamente comprometidas pela precarização do trabalho escolar, especialmente no que se refere às condições de formação e de trabalho docentes. Além disso, há a necessidade de que evidenciem precisão, sintonia, legitimidade e ganhos, para que sejam escolhidas pelos professores, e não impostas e rejeitadas na prática.

No primeiro caso, algumas tentativas de organizar o currículo com base em projetos expõem sua aceitação bem como seus efeitos no direcionamento do trabalho com os alunos, exemplificando, em escolas que vivem condiçóes adversas, o empobrecimento do processo pedagógico. $\mathrm{Na}$ organização pedagógica centrada na transmissão cultural, a função disciplinadora e de controle está presente como parte do processo de ensino e aprendizagem, embutida nas mesmas lições e atividades propostas aos alunos. Já o que se constata no trabalho centrado em projetos, implementado em várias escolas, é que essa função disciplinadora não mais está imbricada nas tarefas de aprendizagem de conteúdos. A movimentação dos alunos em torno dos projetos permite supor que, nessa nova organização do trabalho escolar, eles precisam estar, sobretudo, ocupados ou distraídos, para sua proteção ou para o controle de sua atuação desordeira, própria de seu novo papel, que se distancia daquele que identificava aluno como estudante. Disciplina e controle assumem uma outra conformação, expondo certas inflexões no currículo, num sentido claro de redução e aligeiramento. Observam-se, contudo, possibilidades de outra resultante, já que dentro do mesmo formato ou da mesma estrutura, mantendo as disciplinas da base comum e da parte diversificada, o currículo consegue sofrer arranjos diversos, como variaçōes em metodologias de ensino ou nas relaçôes entre as disciplinas. Tais arranjos podem expressar maior centralidade na aprendizagem dos conteúdos ou em atividades voltadas aos interesses imediatos dos alunos.

A opinião de professores sobre as atuais prescriçōes legais e sobre os Parâmetros Curriculares Nacionais ( $\mathrm{PCN}$ ) foi investigada na citada pes- 
quisa da UNESCO (2004), segundo a qual eles expressam sua aprovação. No entanto, ao enfrentarem na prática os desdobramentos e as conseqüências das decisões legais, rejeitam as medidas e acusam a imposição legal, sobretudo as mesmas prescrições que dizem aprovar, haja vista o exemplo da progressão continuada e o regime de ciclos. Sobre os PCN, sua aprovação não significa execução ou aplicação, mas a possibilidade de utilizar a idéia de projetos ou de temas transversais para tratar questôes sociais relevantes ou, muitas vezes, para organizar atividades leves e atraentes para os alunos.

Nas condiçōes desfavoráveis em que se efetiva o trabalho escolar, os projetos ganham conotações diversas. No caso dos chamados projetos interdisciplinares, por exemplo, o termo "interdisciplinaridade", muitas vezes, é usado apenas para se referir a trabalho conjunto. É diferente do conceito de interdisciplinaridade como estudo de problemas por meio de categorias conceituais que são comuns ou podem transitar entre as diversas disciplinas. É diferente também de estudo multidisciplinar para o trato de temática comum, pois nesses projetos o que é específico das disciplinas pode se dissolver nas diversas tarefas.

Dessa forma, como explica um diretor de escola, mesmo que não haja projetos conjuntos na escola, eles são declarados como artifício para que a escola receba alguns recursos, diante da insuficiência de condiçóes materiais disponíveis para o trabalho pedagógico: "Muito do que a escola indica é só para constar, porque é preciso declarar. Depois se vê o que dá para cumprir". Nessa situação pode ser declarado "algo a partir do que se tem - um professor de ciências desenvolve um projeto de horta com seus alunos, e a escola declara desenvolver um projeto ecológico ou de educação ambiental, inclui nomes de disciplinas e professores participantes. Com mais recursos, depois se vê o que é possível fazer”.

Com tais arranjos convivem, certamente, preocupações com a melhoria da qualidade de ensino e com a superação do caráter fragmentado do currículo, pois, ao buscar elementos para discutir as práticas curriculares no interior da escola, descortina-se um espaço que mostra a presença de conflitos e contradições, assim como de diferenças no trabalho de escolas. Como espaço que abriga crianças, jovens e adultos, a escola tem vida, não cabe em descrições ligeiras em que não se incluem situações de aprendizagem e crescimento, sentimentos de solidariedade e de pertença, assim como diversas iniciativas dos professores para atingir melhorias no proces- 
so de ensino e no aproveitamento dos alunos, além de buscas de atualização pedagógica e de reflexão coletiva sobre a prática.

No que se refere à busca de articulação e organicidade no currículo, vale lembrar que não é de hoje que se apontam sugestões para contornar o problema das disciplinas isoladas e justapostas no currículo. Nos anos de 1960, com a possibilidade de organizar experiências pedagógicas, houve muitas tentativas, como a das escolas renovadas, que propunham a integração curricular pelo método, o qual atingia o trabalho dos professores e as tarefas dos alunos. Também as experiências dos ginásios experimentais e vocacionais em São Paulo apontaram formas de relacionar disciplinas; nesse período, eram usuais, por exemplo, os estudos do meio, que exigiam nítidas articulaçôes entre componentes curriculares.

Na Lei n. 5.692 de 1971 e nos pareceres normativos que se seguiram à sua promulgação, essa busca se expressa na indicação de integração horizontal e vertical dos conteúdos, assim como de integração entre formação geral, no núcleo comum, e formação especial, na parte diversificada. Sobreleva, aí, a articulação dos conteúdos e a sua própria organização, em ordem crescente de complexidade e decrescente de amplitude, deveria ser combinada com seu trato didático de modo que garantisse níveis distintos de articulação em torno de atividades, as quais não deveriam ser sistematizadas, áreas de estudo, em que se daria início a alguma sistematização, e disciplinas, nas quais esse tratamento formalizado seria predominante. A articulação pretendida, é bom lembrar, justificava-se por um modo de compreender a aprendizagem, que exibia o aval científico da psicologia do desenvolvimento, no referencial da epistemologia genética de Piaget. Curiosamente, ainda durante o período de vigência dessas normas, difíceis de vingar porque foram impostas sem legitimidade, complexas demais e sem sintonia com a realidade escolar, permaneceu uma certa busca de integração do currículo, numa direção a práticas mais antigas e conhecidas na escola, relacionando disciplinas de várias formas, inclusive em torno de projetos, e aderindo às mais recentes chamadas por interdisciplinaridade.

A legislação atual, que se traduz principalmente na Lei de Diretrizes e Bases da Educação Nacional (LDB), de 1996, e nas Diretrizes Curriculares Nacionais (DCN), mantém indicaçōes anteriores, como a estrutura curricular em torno de disciplinas organizadas em base comum nacional e parte diversificada; em seu detalhamento retoma-se a idéia mais antiga, de projetos, reitera-se o valor da interdisciplinaridade e 
acrescenta-se a indicação de transversalidade no currículo. Propõe-se, com tal tratamento, que se integrem as disciplinas da atual base comum nacional a princípios ou temas de vida cidadã, que podem desenvolverse na forma de projetos, compondo a parte diversificada do currículo, ou como temas transversais.

O desenvolvimento de projetos, numa certa perspectiva de interdisciplinaridade, que parece fazer sentido na escola, como já foi afirmado, situa-se na continuidade das práticas que se firmaram nas tentativas de articular ou integrar o currículo. Analisar o que está em jogo nessas tentativas desenvolvidas no interior da escola pode ajudar a compreender essa melhor aceitação dos projetos, e também as dificuldades na implementação dos ciclos.

Observa-se que nas iniciativas dos professores em busca de organizar o ensino de modo mais articulado e conjunto está presente, ainda, a expectativa de que os alunos adquiram habilidades comuns ao trato dos diversos componentes. $\mathrm{Na}$ busca de relaçôes entre os componentes do currículo, pretende-se, então, beneficiar e facilitar o trabalho de vários professores de um mesmo grupo de alunos, bem como atingir melhoria de rendimento.

Quando a maior ênfase da integração proposta se situa no ensino, ou seja, no seu método de organização, recaem algumas conseqüências sobre a aprendizagem dos alunos, que passam a utilizar, nas diferentes disciplinas, procedimentos comuns de acesso ao conhecimento, de utilização de conceitos, de organização das tarefas. São procedimentos como consulta prévia e organização inicial dos assuntos a discutir em aula com o professor, elaboração de planos pessoais de distribuição, realização e avaliação de tarefas em determinados períodos de tempo (como semanas ou quinzenas), que oferecem aos alunos margens diversificadas de movimentação e de atendimento às suas necessidades de aprendizagem. Também para articular o ensino em torno de temas ou projetos, a atividade dos alunos tem de se configurar em novos parâmetros, que produzirão determinadas conseqüências no processo de aprendizado e no que será apropriado.

Ora, se o foco das intervenções é a aprendizagem, e procura-se evitar truncamentos e fragmentação nesse processo, há conseqüências previsíveis sobre o ensino, ou seja, sobre a atuação docente. Em modelos impostos pelas reformas ou pelos sistemas de ensino, exigem-se alteraçóes muitas vezes não escolhidas e não compreendidas pelos professores. 
Compreende-se, assim, que na atual organização em ciclos, com base na aprendizagem contínua, são nítidas as dificuldades para mudar o encadeamento seriado. As reações às mudanças apontam para sua falta de sintonia com a prática, causando estranhamento e rejeição dos professores. Apesar de, como se sabe, a organização por ciclos não constituir novidade estranha à escola, há que se considerar cuidadosamente a persistência da seriação, como indicador de sua consistência na condução da prática pedagógica. Ocorre que, na atual reformulação do ensino, propostas que se baseiam na organização de um percurso contínuo em que os alunos não sejam reprovados, mas possam prosseguir com acompanhamento adequado às suas diferentes necessidades, supõem e exigem que o professor mude a organização temporal e a seqüência do que vai desenvolver com os alunos, que mantenha o ritmo de atividade e participação dos alunos mesmo sem a ameaça da reprovação, que consiga acompanhar grupos heterogêneos, oferecendo trabalho e atendimento diversificados para uma mesma turma de alunos. No entanto, o professor nunca aprendeu a trabalhar assim, não experimentou essa organização, sequer como aluno, e tais práticas não têm lugar numa tradição de escola de massa, que se sustenta no atendimento indiferenciado e homogeneizador, para dar conta de grupos numerosos e heterogêneos, distanciados do que se faz legítimo na cultura da escola.

Nos dois exemplos comentados, cruzam-se fatores que comprometem a atuação da escola. Por bom senso já se pode afirmar que qualquer que seja a direção, as mudanças exigem condições de trabalho quase sempre ausentes em nossas escolas, como apontado inicialmente. Também é evidente que, tanto no caso dos projetos como na implementação dos ciclos, há questôes muito mais complexas que as qualidades das medidas e a boa vontade das escolas para realizá-las. As promessas da atual reforma relativas à melhoria do quadro da escolarização dissolvem-se ou, pelo menos, tomam a feição concreta de um projeto de governo que desconhece ou não se importa com a realidade da nossa escola pública, que não destoa da vida de seus usuários e que é a instituição na qual se expressa a face mais dura da organização econômica e social em que se produz a vida de nossas crianças e jovens.

A ordem social resultante da nova organização das relações capitalistas recai sobre os atendimentos públicos como a escola, de modo implacável, empobrecendo mais o seu já pobre trabalho, discriminando mais fortemente os seus sujeitos, afastando de seu interior todas as cri- 
anças e jovens que tenham alguma possibilidade mínima de juntar-se a grupos que pagam por sua educação nas escolas privadas.

$\mathrm{O}$ quadro de empobrecimento, deterioração social e as conseqüentes transformações nos modos de compreender a vida e o mundo, que se vive atualmente, de modo especial no Brasil e na América Latina, tem relação com a crise da escola, ou seja, com o abalo e o desmonte de um modo de atuar socialmente, desestabilizando seu funcionamento.

O desfecho da crise não parece que se dê na direção do fim da escola, peça indispensável no conjunto das medidas de convencimento e conformidade social à ordem estabelecida. $\mathrm{Na}$ luta em favor de transformações sociais, ainda que se acumulem denúncias e a busca por saídas, mesmo seus críticos mais ferozes reconhecem que a escola é necessária como parte de um processo de civilização, cujas conquistas precisam ser preservadas. Acima de tudo, a escola é reconhecida como espaço insubstituível de acolhimento das novas gerações, com possibilidades de se tornar mais igualitária e livre de preconceitos, e de permitir-lhes que conheçam sua cultura, possam analisar a sociedade, adquiram instrumentos para a crítica, a reflexão e até, quem sabe, para a criação de alternativas, diante das poderosas determinações que se impóem, inegavelmente.

Os dados aqui expostos indicam a gravidade da situação atual de crise e o delineamento de um novo modo de organizar a prática e o currículo, em que se vai destituindo o lugar do conhecimento e da reflexão. É evidente o serviço à ordem vigente de estudos que reduzam os problemas a questóes de gestão e de ineficiência da escola, ou a impropriedades e irrelevância do currículo, já que a relação de desvalorização e relativização total do conhecimento se articula ao desmonte da escola pública e acompanha o movimento de desvalorização das pessoas que usam a escola e fazem dela seu posto de trabalho.

Recebido e aprovado em outubro de 2004.

\section{Nota}

1. As questões sociais indicadas vêm da pauta dos programas internacionais de educação para todos, desde Jomtien, em 1990, e atrelam a educação com um novo projeto social, de suporte à reformulação política e econômica do neoliberalismo. 


\section{Referências bibliográficas}

BRASIL. Ministério da Educação. Instituto Nacional de Estudos e Pesquisas Educacionais. Geografia da Educaçāo Brasileira. Brasília, 2002.

CHACUR, C.R.S.L.; DIAS DA SILVA, M.H.G.F. O ensino de $5^{\mathrm{a}}$ a $8^{\mathrm{a}}$ séries: pistas para compreensão da escola pública. Boletim do Departamento de Didática: a situação de ensinar e aprender. Araraquara, ano IX, n. 6, 1990. p. 29-40.

CORAGGiO, J.L. Desenvolvimento humano e educação. São Paulo: Cortez, 2000.

DALE, R. Globalização e educação: demonstrando a existência de uma "cultura educacional mundial comum" ou localizando uma "agenda globalmente estruturada para a educação"? Educação \& sociedade, Campinas, v. 25, n. 87, maio-ago. 2004. p. 423-460.

FERNANDES, F. Educação e sociedade no Brasil. São Paulo: Dominus/ EDUSP, 1966.

FERREIRINHO, V.C. Começar de novo: práticas de socialização do professor em início de carreira. 2004. Dissertação (mestrado) - Pontifícia Universidade Católica de São Paulo, São Paulo.

GUARNIERI, M.R. Tornando-se professor: o início na carreira docente e a consolidação na profissão. 1996. Tese (doutorado) - Universidade Federal de São Carlos (UfSCAR), São Carlos.

LOURENCETTI, G.C. Mudanças sociais e reformas educacionais: repercussões no trabalho docente. 2004. Tese (doutorado) - Faculdade de Ciências e Letras, Universidade Paulista Júlio de Mesquita Filho (UNESP), Araraquara.

PAIVA, M.M. Professor não habilitado: agora um sujeito ocultado no magistério público paulista. 2002. Dissertação (mestrado) - Pontifícia Universidade Católica de São Paulo, São Paulo.

PAIVA, V. et al. Revolução educacional e contradições da massificação do ensino. Contemporaneidade e educação, n. 3, 1998. p. 44-99.

PATINHA, V.A. Professor não habilitado: um sinal da crise na educação. 1999. Tese (doutorado) - Pontifícia Universidade Católica de São Paulo, São Paulo. 
PESSANHA, E.C. Ascensão e queda do professor. São Paulo: Cortez, 2001. SINISCALCO, M.T. Perfil estatistico da profissão docente. São Paulo: Moderna, 2003.

UNESCO. Perfil dos professores brasileiros: o que fazem, o que pensam, o que almejam... São Paulo: Moderna, 2004.

WEREBE, M.J.G. Grandezas e misérias do ensino no Brasil. São Paulo: Difusão Européia do Livro, 1968. 